\title{
Arsenic Speciation in Environmental Samples Using Different Acid Concentrations and Ultrasonic Extraction for the Determination by HG-FAAS
}

\author{
Bianca S. Pinheiro, Luana L.S. Gimenes, Ailton José Moreira, Carolina D. Freschi, \\ and Gian Paulo G. Freschi* \\ LAFFEQ, Institute of Science and Technology, Federal University of Alfenas, \\ UNIFAL-MG, 37715-400, Poços de Caldas - MG, Brazil
}

\begin{abstract}
This work describes a simple method for As(III), As(V), and dimethylarsinicacid (DMA) speciation by the selective determination of organic and inorganic arsenic forms using just flow injection (FI) and on-line hydride generation (HG) coupled to a flame atomic absorption spectrometer (HG-FAAS). The speciation method is based on As(III) determination using $1.2 \%\left(\mathrm{~m} \mathrm{v}^{-1}\right)$ $\mathrm{NaBH}_{4}$ and $2 \%\left(\mathrm{v} \cdot \mathrm{v}^{-1}\right) \mathrm{HCl}$ solution as the carrier, and reduction of $\mathrm{As}(\mathrm{V})$ to $\mathrm{As}(\mathrm{III})$ using $1.2 \%$ $\left(\mathrm{m} \mathrm{v}^{-1}\right) \mathrm{NaBH}_{4}$ and high concentrations of $\mathrm{HCl}\left[10 \%\left(\mathrm{v} \cdot \mathrm{v}^{-1}\right)\right]$ as the pre-reduction agent to inorganic arsenic (iAs) determination. For the selective determination of As(III) and DMA, nitric acid was used once at high $\mathrm{HNO}_{3}[2 \%$ $\left.\left(\mathrm{v} . \mathrm{v}^{-1}\right)\right]$ concentration to quantify As(total) [As(III) and DMA]. Thus, the species determinations were possible by changing the acid and its concentration.

Using optimum instrumental conditions for the reagent solutions $\left(\mathrm{NaBH}_{4}, \mathrm{NaOH}\right.$, and $\mathrm{HCl}$ ),
\end{abstract}

carrier gas flow rates (argon), flame composition (airacetylene), and carrier solution rates for on-line generation of arsenic hydride, the method was applied to the analysis of soil and sediment samples. Ultrasonic (US) extraction was used as the sample preparation method with $1.0 \mathrm{~mol} \mathrm{~L}^{-1} \mathrm{HCl}$ solutions, resulting in values close to $100 \%$. A comparison of the proposed method with other ultrasonic extraction methods showed that the proposed ultrasonic liquid extraction (USLE) method results in low detection limits and requires low sample consumption. Recovery tests were employed to ensure the accuracy of the speciation method, and satisfactory results in the 83-100\% range were obtained for the As species. The precision of the measurements $(n=12)$, calculated as the relative standard deviation, was below $8.0 \%$. The limits of detection (LOD) for As(III), As(V), and DMA in soil and sediment samples were $3.1,5.7$, and $3.8 \mu \mathrm{g} \mathrm{g}^{-1}$, respectively.

\section{INTRODUCFTION}

Arsenic (As) is found in nature in various forms of inorganic and organic species. The inorganic forms such as As(III) and As(V) are considered the most toxic and are easily absorbed into the body depending on solubility, $\mathrm{pH}$, and chemical form. The organic forms, such as inoffensive arsenobetaine (AB) and others are "potentially"

\footnotetext{
Corresponding autbor.

E-mail: gian.freschi@unifal-mg.edu.br

Tel.: +553536974756
}

toxic or non-toxic. The different As species are distributed into the environment by natural or anthropogenic sources into water, soil, and many products. Arsenic compounds have a well-defined toxicity order of arsine: $\left(\mathrm{AsH}_{3}\right)>$ arsenic As(III) > arsenic As(V) > alkyl arsenic acid > elemental $(1,2)$. Because of the different toxicities of As, new methods and techniques have focused on identifying these arsenic species (3-5) which allow for a more accurate assessment of toxicity, bioavailability, and accu- mulation into the ecosystem. The different techniques used for arsenic determination at low concentrations in a wide range of samples include spectrophotometry (6), atomic fluorescence spectrometry (AFS) (7), electrothermal atomic absorption spectrometry (ETAAS or GFAAS) (8), inductively coupled plasma mass spectrometry (ICP-MS) (9), laser-induced fluorescence spectrometry (LIF), laserenhanced ionization spectrometry (LEI) (10), and biosensors (11). Some of these techniques can be prohibitive in cost or lack in selectivity, simplicity, and sensitivity.

An alternative technique widely used for this purpose is hydride generation (HG), which produces volatile hydrides due to the chemical reduction of a component with a reducing agent in acidic solution, typically sodium tetrahydroborate $\left(\mathrm{NaBH}_{4}\right)$ (12). Hydride generation coupled with atomic absorption spectrometry (HG-AAS) has been widely applied for the determination of hydride-forming elements and is considered one of the most efficient and sensitive analytical techniques (13). It offers improved sensitivity, selectivity, and simplicity in the determination of As at low concentrations, allows discerning species to form by volatile hydrides (14), and is currently the most popular technique for routine analysis $(15,16)$.

In recent years, the interest in a more simple and applicable methodology for arsenic speciation in environmental samples has increased and has been the object of study by researchers (17). The methods most employed for the speciation of As are hyphenated 
techniques, such as high-pressure liquid chromatography (HPLC) which is very costly and time-consuming. A less expensive alternative to chromatography is hydride generation which uses different conditions or additives to determine a specific species selectively (18).
This work developes an efficient and simple method for As speciation in environmental samples using different acids and concentrations, followed by HG-FAAS determination after ultrasonic liquid extraction (USLE).

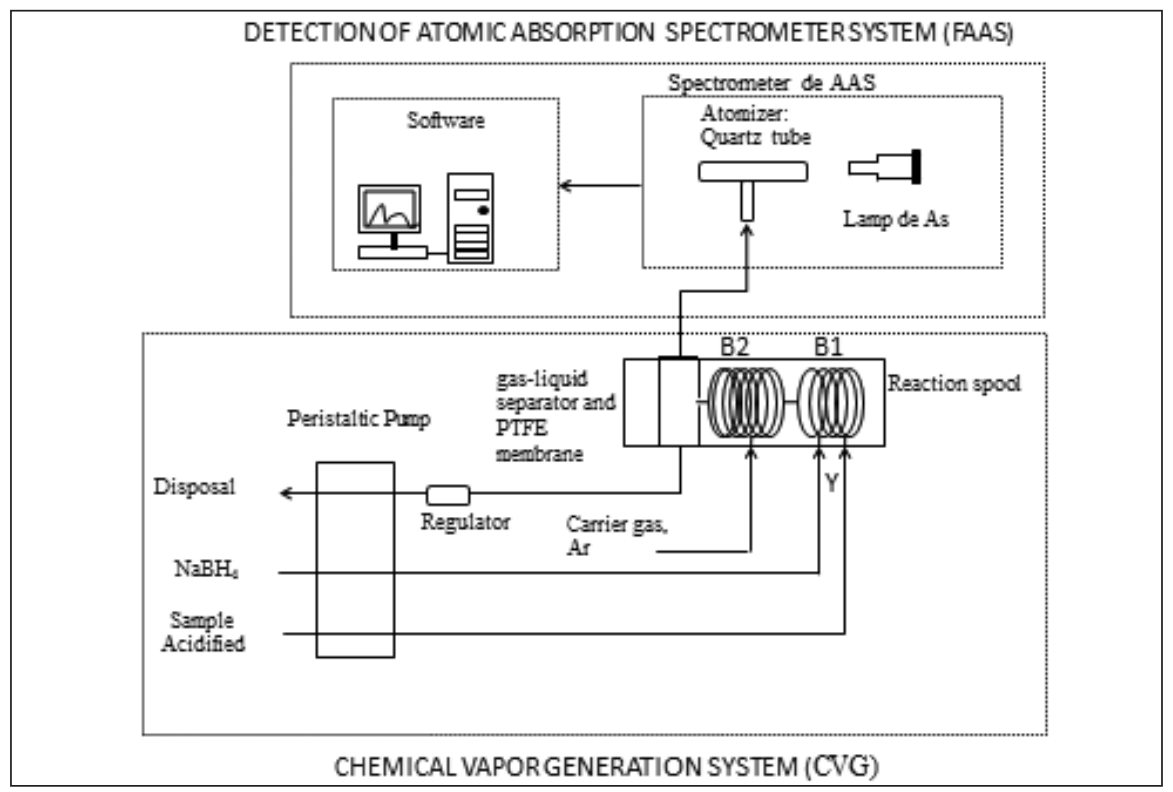

Fig. 1. Schematic diagram of THB-HG-AAS system.

TABLE I

Optimum Parameters Used for THB-HG-AAS

\begin{tabular}{|c|c|}
\hline Parameters & Conditions \\
\hline Wavelength & $193.7 \mathrm{~nm}$ \\
\hline Slit width & $0.5 \mathrm{~nm}$ \\
\hline LampCurrent & $10 \mathrm{~mA}$ \\
\hline Background correction & On \\
\hline Stand by time & $30 \mathrm{~s}$ \\
\hline Analysis time & $10 \mathrm{~s}$ \\
\hline Number of replicates & 3 \\
\hline Flame (Ar/acetylene) & 13.5 $\mathrm{L} \mathrm{min}^{-1}(\mathrm{Ar}) ; 1.5 \mathrm{~L} \mathrm{~min}^{-1}$ (acetylene) \\
\hline Drag the flow of gas (Argon) & $100 \mathrm{~mL} \cdot \mathrm{min}^{-1}$ \\
\hline Sample & Water, sediment and plants \\
\hline \multicolumn{2}{|l|}{ Speed peristaltic pump } \\
\hline \multicolumn{2}{|l|}{30} \\
\hline Reaction coil & $30 \mathrm{~cm}$ \\
\hline $\mathrm{NaBH}_{4}$ & $1.2 \%\left(\mathrm{~m} . \mathrm{v}^{-1}\right)$ \\
\hline Sample flow & $1.5 \mathrm{~mL} \mathrm{~min}^{-1}$ \\
\hline Charger flow & $1.25 \mathrm{~mL} \mathrm{~min}^{-1}$ \\
\hline Disposal flow & $7.5 \mathrm{~mL} \mathrm{~min}^{-1}$ \\
\hline
\end{tabular}

\section{EXPERIMENTAL}

\section{Instrumentation}

The determination of As(III), As(V), and dimethylarsenic (DMA) was performed using an Agilent 240FS flame atomic absorption spectrometer (Agilent Technologies, Santa Clara, CA, USA), equipped with an air/acetylene burner (13.50/1.50 $\mathrm{mL} \mathrm{min}^{-1}$ ) and a deuterium lamp for background correction. A hollow cathode lamp (HCL) was the radiation source and operated at $193.7 \mathrm{~nm}$ with a current of $10 \mathrm{~mA}$.

Hydride generation was performed with a Model Ismatec 8 peristaltic pump (Ismatec, Wertheim, Germany) and Tygon ${ }^{\circledR}$ tubing was used to pump the solutions. A reaction spool was connected to the gas-liquid separator with a Teflon ${ }^{\circledR}$ polytetrafluoroethylene (PTFE) membrane $(0.2 \mu \mathrm{m})$ attached to the atomizer. A stream of high purity argon (99.999\%, White Martins, Brazil) was used to load the arsine (formed in the reaction spool) into the gasliquid separator and then to the quartz cell located above the flame air/acety-lene spectrometer. The flow rates used in the hydride generator were $1.5 \mathrm{~mL} \mathrm{~min}^{-1}$ for the sample, $1.25 \mathrm{~mL} \mathrm{~min}^{-1}$ for the charger, and $7.5 \mathrm{~mL} \mathrm{~min}^{-1}$ for the reducing agent. Figure 1 is a schematic diagram of the system and the instrumental and operating conditions are listed in Table I.

\section{Solutions, Reagents, and Materials}

All standard solutions were prepared from analytical grade reagents. Ultrapure water was obtained using a Milli-Q ${ }^{\circledR}$ purification system (Millipore Corporation, Bedford, MA, USA) with a minimum resistivity of $18.0 \mathrm{M} \Omega \cdot \mathrm{cm}^{-1}$.

The standards were stored in Nalgene ${ }^{\circledR}$ high density polypropylene bottles and kept under refrig- 
eration. Before use, all glassware was demineralized by immersion in a bath of nitric acid $10 \%\left(\mathrm{v} . \mathrm{v}^{-1}\right)$ for 24 hours, then rinsed exhaustively with ultrapure water. The As(III) standard solution (1000 $\mathrm{mg} \mathrm{L}^{-1}$ ) was prepared by dissolving $0.132 \mathrm{~g}$ of $\mathrm{As}_{2} \mathrm{O}_{3}$ (Fluka, Buchs, Switzerland) in $30 \% \mathrm{NaOH}\left(\mathrm{m} \cdot \mathrm{v}^{-1}\right)$, then neutralized with approximately $3.0 \mathrm{~mL}$ of concentrated $\mathrm{HCl}$ (E. Merck, Darmstadt, Germany) producing a $\mathrm{pH}$ of 5.06, and the final solution brought to $100-\mathrm{mL}$ volume with water. The stock solutions of As(V) and dimethylarsenic (DMA) were prepared by dissolution of $0.07767 \mathrm{~g}$ of $\mathrm{As}_{2} \mathrm{O}_{5}$ (Fluka, Buchs, Switzerland) and $0.0920 \mathrm{~g}$ $\left(\mathrm{CH}_{3}\right)_{2} \mathrm{AsO}_{2} \mathrm{H}$ (Sigma-Aldrich, USA), dissolved in ultrapure water (brought to 50-mL volume), and stored in the refrigerator at $4{ }^{\circ} \mathrm{C}$ to preserve the species. The analytical solutions were prepared daily from stock solutions with $2 \%$ and $10 \%$ (v. $\left.{ }^{-1}\right) \mathrm{HCl}$. Sodium tetrahydroborate $\left(\mathrm{NaBH}_{4}\right)$ (E. Merck, Germany) was used as the reducing agent for the formation of the hydrides, stabilized with a sodium hydroxide solution [0.5\% (m. $\left.\left.\mathrm{v}^{-1}\right) \mathrm{NaOH}\right]$ (Merck, Germany). Various concentrations of $\mathrm{HCl}$ were evaluated for the prereduction of As(V), As(III), and DMA.

From the concentrated nitric and hydrochloric acids, 100-mL solutions containing $40 \mathrm{~mL}$ of acids $\left[40 \%\left(\mathrm{v} . \mathrm{v}^{-1}\right)\right]$ were prepared. From these solutions, the study of intermediate solutions using different inorganic acids was performed.

\section{Samples and Sample Prepara- tion}

Three water and plant samples were randomly collected from the river's edge at Bortolan and INB (Insdustrias Nucleares do Brasil) in Poços de Caldas, Brazil, and transferred into plastic bags. For the river sediment analysis, three samples were collected using a core sample tube made of polyvinyl chloride (PVC) with a removable top. The tube was inserted into the sediment at $30-\mathrm{cm}$ depth, and the samples placed into plastic containers. The plant and sediment samples were transported in coolers to the laboratory, where they were dried, sieved at 2.00-mm grating, homogenized, and stored at ambient temperature $\left(24^{\circ} \mathrm{C}\right)$ in paperboard boxes without preservatives or reagents. The samples were sonicated using a USC-700 ultrasonic bath (UNIQUE, Brazil), with 1-liter capacity, $50 \mathrm{~Hz}$ frequency, power of $55 \mathrm{~W}$ for As extraction. Before ultrasonic liquid extraction (USLE) of the samples (plant and sediment), the bath was mapped to choose the better position for the sample. Mapping of the ultrasonic bath was performed according to the outline in the literature (20). After sonication, the solutions (medium) were analyzed in a molecular absorption spectrometer at $352 \mathrm{~nm}$. This study showed no uniform distribution in the ultrasonic field and the position near the transducer has a higher intensity sonication, thus indicating a higher efficiency in extracting the samples. This position was used for the plant and sediment sample preparation using USLE.

To check the accuracy, different quantities of As(III), As(V), and DMA were added to three sediment and plant samples before sample preparation. For this step, a portion $(1.0 \mathrm{~g} \pm 0.1 \mathrm{mg})$ of sediment or plant was weighed and placed into 15-mL polypropylene tubes, then $10 \mathrm{~mL}$ of $\mathrm{HCl}\left(6.0 \mathrm{~mol} \mathrm{~L}^{-1}\right)$ was added as the extraction solution. The samples were sonicated for 10 minutes, the solution centrifuged at $4000 \mathrm{rpm}$ for 10 minutes, and filtered in a cellulose acetate membrane $(0.45 \mu \mathrm{m})$ to remove any suspended solids before speciation. The leachate was made up to 50-mL volume with ultrapure water, and arsenic determination was carried out by HG-FAAS using different carriers. Blanks were treated in the same way for each acidic medium. The performance of the extraction solution was evaluated by adding $50.0 \mu \mathrm{g} \mathrm{g}^{-1}$ of each species to randomly chosen samples, then USLE was carried out with an ultrasonic bath at $55 \mathrm{KHz}$. Then, the determination of As by HG-FAAS was done. For arsenic speciation, $10.0 \mathrm{~mL}$ supernatant and the optimum conditions of $\mathrm{NaBH}_{4}$ and $\mathrm{HCl}$ or $\mathrm{HNO}_{3}$ (carrier) were used. All samples were submitted to a triplicate procedure.

\section{Procedure}

Speciation of the different forms of arsenic was performed with the proposed method where DMA and As(V) were pre-reduced to As(III), using a variation in acid concentration for pre-reducing/generating the hydride steps, and then detection by HG-FAAS. For the generation of arsine $\left(\mathrm{AsH}_{3}\right)$, the gas flow carrier, standard/sample flow, prereducing and reducing steps, and reaction coil were evaluated. The optimized operating parameters for the system were used as listed in Table I. The schematic diagram of the system is shown in Figure 1. The analytical speciation of As was done by the determination of iAs [As(III)+As(V)] and As(III) by employing different $\mathrm{HCl}$ concentrations and of As(total) [DMA+As(III)] by using $\mathrm{HNO}_{3}$. The concentration of As(V) was obtained by the difference between the iAs and As(III) values, and DMA was determined by the difference between the As(total) and As(III) values. The samples (water, plants, and sediments), carrier ( $\mathrm{HCl}$ ) solution, and reducing $\left(\mathrm{NaBH}_{4}\right)$ solution were pumped into the HG gas/liquid separator system using three different tubes: $0.76 \mathrm{~mm}$ i.d. for the carrier and reducing solutions and 2.29 $\mathrm{mm}$ i.d. for the sample solutions. For arsine generation $\left(\mathrm{AsH}_{3}\right)$, the aspiration rates of the sample/ standards, carrier and reducing 
solutions were $9.0,1.0$, and $1.0 \mathrm{~mL}$ $\min ^{-1}$, respectively.

Different concentrations and types of acid solutions were used for As [iAs and As(total)] speciation. For iAs [As(III) + As(V)] determination, $10 \%\left(\mathrm{~V} \cdot \mathrm{v}^{-1}\right) \mathrm{HCl}$ was used as the standard/samples medium and for As(III) determination, 2\% (v. $\left.\mathrm{v}^{-1}\right)$ $\mathrm{HCl}$ standard/samples medium. Speciation was possible by using $2 \% \mathrm{HCl}$, and $\mathrm{As}$ (III) is determined because this form generates hydrides. In $10 \% \mathrm{HCl}$, both As forms generate hydrides and then iAs is determined. The DMA was quantified using a similar procedure, where As(III) was determined using $15 \%\left(\mathrm{v} . \mathrm{v}^{-1}\right) \mathrm{HNO}_{3}$ in standard/ samples medium and As(total) [DMA+As(III)] determination was done in $2 \%\left(\mathrm{v} \cdot \mathrm{v}^{-1}\right) \mathrm{HNO}_{3}$ standard/ samples medium. Similar to iAs, the difference in the quantities found in $2 \%\left(\mathrm{v} . \mathrm{v}^{-1}\right) \mathrm{HNO}_{3}$ and $15 \%\left(\mathrm{v} . \mathrm{v}^{-1}\right)$ $\mathrm{HNO}_{3}$ is the exact DMA amount.

The arsine was conducted to the cell quartz insert on the burner/atomizer using a 100-mL $\mathrm{min}^{-1}$ argon flow rate. The determinations of the calibration curves were within the $20-100 \mu \mathrm{g} \mathrm{L}^{-1}$ range.
Since no certified reference materials with different arsenic forms are available, the speciation accuracy was evaluated by recovery tests using water, sediment, and plant samples spiked with $50.0 \mu \mathrm{g} \mathrm{L}^{-1}$ As(III) + As(V) + DMA before extraction. The precision of the method was checked by means of calculating the relative standard deviation (\%RSD) of the sample measurements. The limit of detection (LOD) and limit of quantification (LOQ) for As(III), iAs, and As(total) were calculated according to IUPAC recommendations (25).

\section{RESULTS AND DISCUSSION}

\section{Effect of Different Concentra-} tions of $\mathrm{HCl}$ and $\mathrm{HNO}_{3}$ in $\mathrm{HG}$ FAAS Analysis for Different As Species

The variation of $\mathrm{HCl}$ and $\mathrm{HNO}_{3}$ concentration was studied in order to establish the best answer to the proposed method and the possibility of speciation of arsenic species. Figure 2a shows the responses obtained by optimization of different quantities of $\mathrm{HCl}$ into the standards and samples. The influence of $\mathrm{HCl}$ was performed in the concentration range of 2 to $15.0 \%$ $\left(\mathrm{v} . \mathrm{v}^{-1}\right)$, for $\mathrm{NaBH}_{4}$ at $1.2 \%\left(\mathrm{~m} \cdot \mathrm{v}^{-1}\right)$, for carrier $\mathrm{HCl} 2 \%\left(\mathrm{v} \cdot \mathrm{v}^{-1}\right)$, and for the As species $50.0 \mu \mathrm{g} \mathrm{L}^{-1}$. In this study it was observed that the absorbance of As(III) varies little at the concentration ranges studied. As(V) has a higher absorbance when the $\mathrm{HCl}$ concentration was varied from $8.0 \%\left(\mathrm{v} . \mathrm{v}^{-1}\right)$ to $12.0 \%$ $\left(\mathrm{v} . \mathrm{v}^{-1}\right)$, possibly due to the more efficient hydride generation of As(V). For the DMA organic species, the absorbance increased linearly with increasing concentrations of $\mathrm{HNO}_{3}$, from 2 to $15.0 \%$ (v.v-1), possibly due to the reduction of DMA to As(III) in higher amounts of nitric acid. This study showed that the absorbance of As(III) varied little over a wide concentration range studied, observing higher absorbance values at $\mathbf{8 . 0 \%}$ $\left(\mathrm{v} . \mathrm{v}^{-1}\right)$, but no significant variation was observed for As(III). The absorption of DMA decreased sharply (Figure 2b) and linearly with increasing amounts of $\mathrm{HNO}_{3}$, indicating the oxidation of As(V). No absorbance change for As(V) was observed in the range studied (Figure 2b). This figure shows that at low concentrations of nitric acid (2.0\%), quantification of As(III) and DMA [As(total)] is possible. However, when high concentrations are employed (15\%), only As(III) is
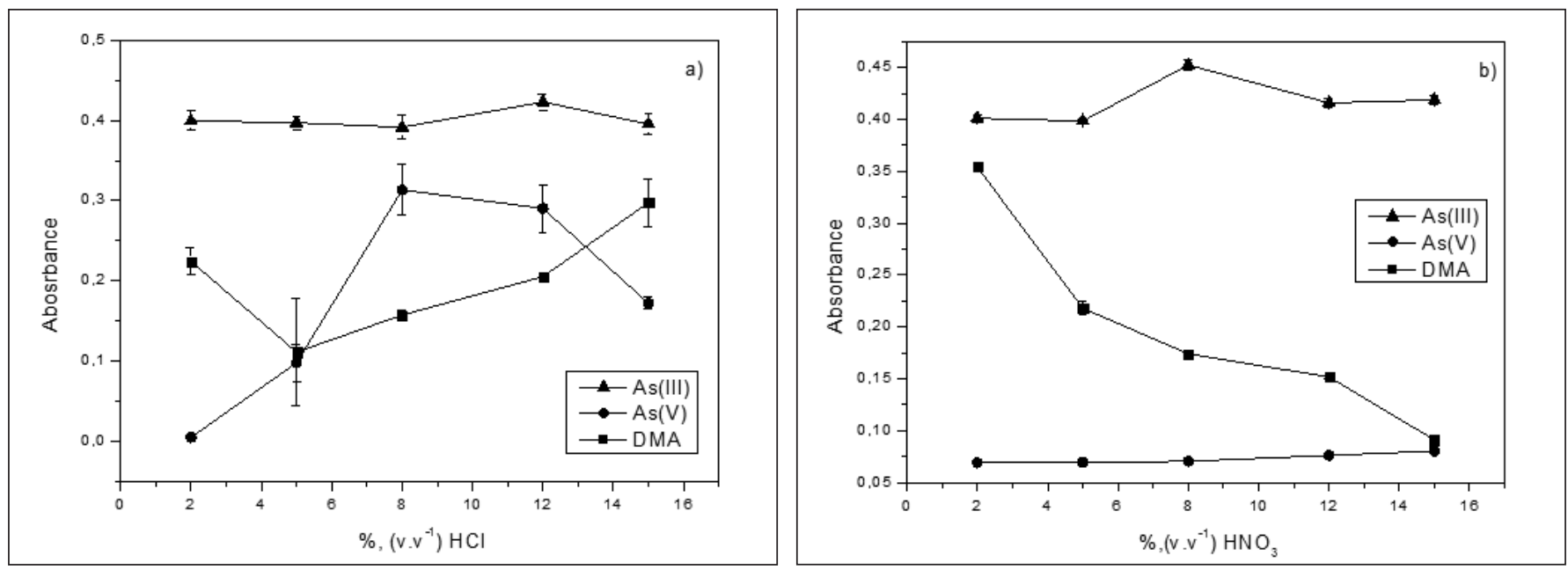

Fig.2. Influence of different acids in THB-HG-AAS system for different kinds of As(III), As (V), and DMA. (a) Hydrochloric acid ( $\mathrm{HCl}$ ) and (b) Nitric acid $\left(\mathrm{HNO}_{3}\right)$. 


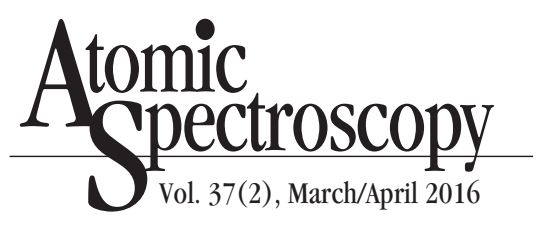

quantified. Hence, a variation in acid concentration allowed As speciation and the selective determination of As(III), iAs, and As(total). After this quantification, the amount of As(V) and DMA is obtained by using a simple mathematical subtraction.

\section{Quantification of As(III), As(V), and DMA Using HG-FAAS}

The calibration curves in Figure 3 ( $a, b$, and $c$ ) were constructed for the determination of As(III), As(V), and DMA using different concentrations of $\mathrm{HCl}$ and $\mathrm{HNO}_{3}$. Three cali- bration curves were used for As speciation in different media:

(a) $15 \%\left(\mathrm{v} \cdot \mathrm{v}^{-1}\right) \mathrm{HNO}_{3}$ for As(III),

(b) $10 \%\left(\mathrm{~V} . \mathrm{V}^{-1}\right) \mathrm{HCl}$ for $\mathrm{As}(\mathrm{V})$, and

(c) $2 \%\left(v . v^{-1}\right) \mathrm{HNO}_{3}$ for DMA. The

(b) and (c) curves were built by subtracting the As(III) concentration of iAs determined in $10 \%\left(\mathrm{~V} . \mathrm{V}^{-1}\right)$ $\mathrm{HCl}$ for $\mathrm{As}(\mathrm{V})$ quantification, and of As(total) in $2 \%\left(\mathrm{v} \cdot \mathrm{v}^{-1}\right) \mathrm{HNO}_{3}$ for DMA quantification. Thus, the analytical curves for As speciation demonstrated that the proposed method has good linearity between points and good sensitivity compared to total determination. The

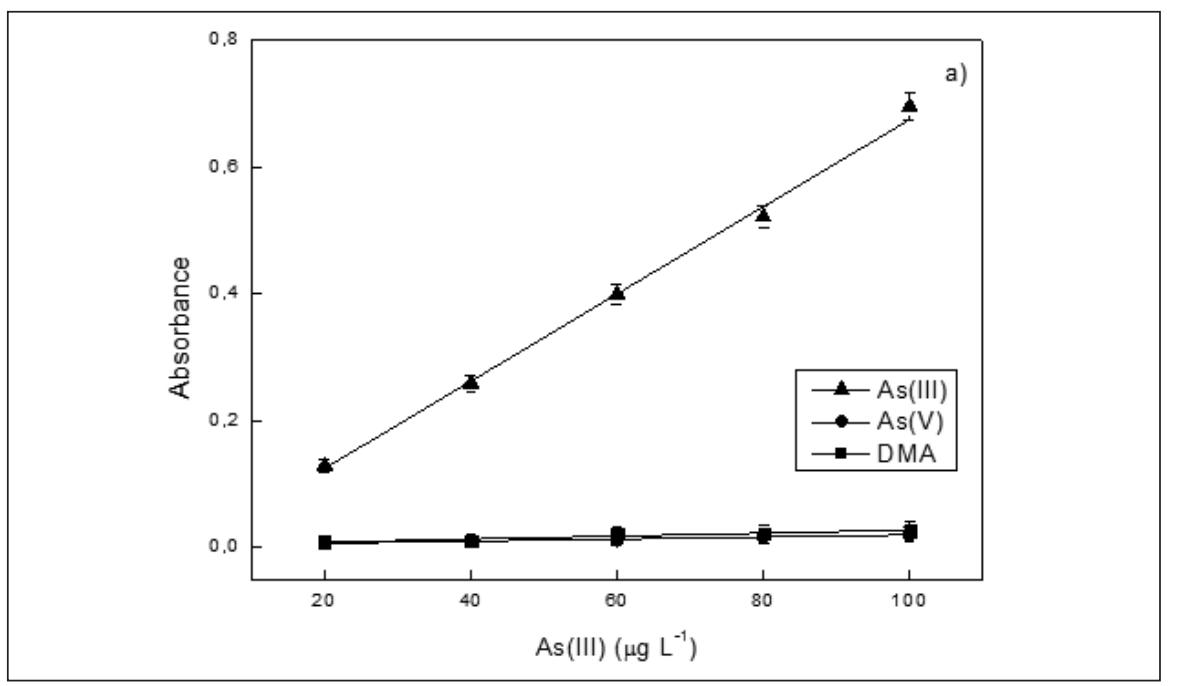

results of this process show that only a change in acid concentration is required for quantifying the As species without use of expensive techniques or time-consuming methods.

The speciation was done first in $\mathrm{HNO}_{3} 15 \%\left(\mathrm{v} . \mathrm{v}^{-1}\right)$ that allowed the As(III) determination only; second, the As(total) determination was done in $\mathrm{HNO}_{3} 2 \%\left(\mathrm{v} \cdot \mathrm{v}^{-1}\right)$, and third, the iAs determination was done in $\mathrm{HCl} 10 \%\left(\mathrm{v} \cdot \mathrm{v}^{-1}\right)$. After the quantifications in different media, the As(III) amount is subtracted from iAs to quantify As(V), and As(total) is determined to quantify total DMA.

\section{Sample Preparation}

According to the results, the $\mathrm{HCl}$ solutions showed an appreciable performance, recovery values above $80 \%$, and thus were selected for better evaluation. The accuracy of the extraction procedure was evaluated by recovery tests using the sediment and plant samples using $6.0 \mathrm{~mol} \mathrm{~L}^{-1} \mathrm{HCl}$ solutions. Figure 4 shows the extraction results obtained by the proposed method when a quantity of As(III), As(V), and DMA were added to prepare $130 \mu \mathrm{g} \mathrm{L}^{-1}$ of As(III) + As(V) + DMA in a sample. As can be seen
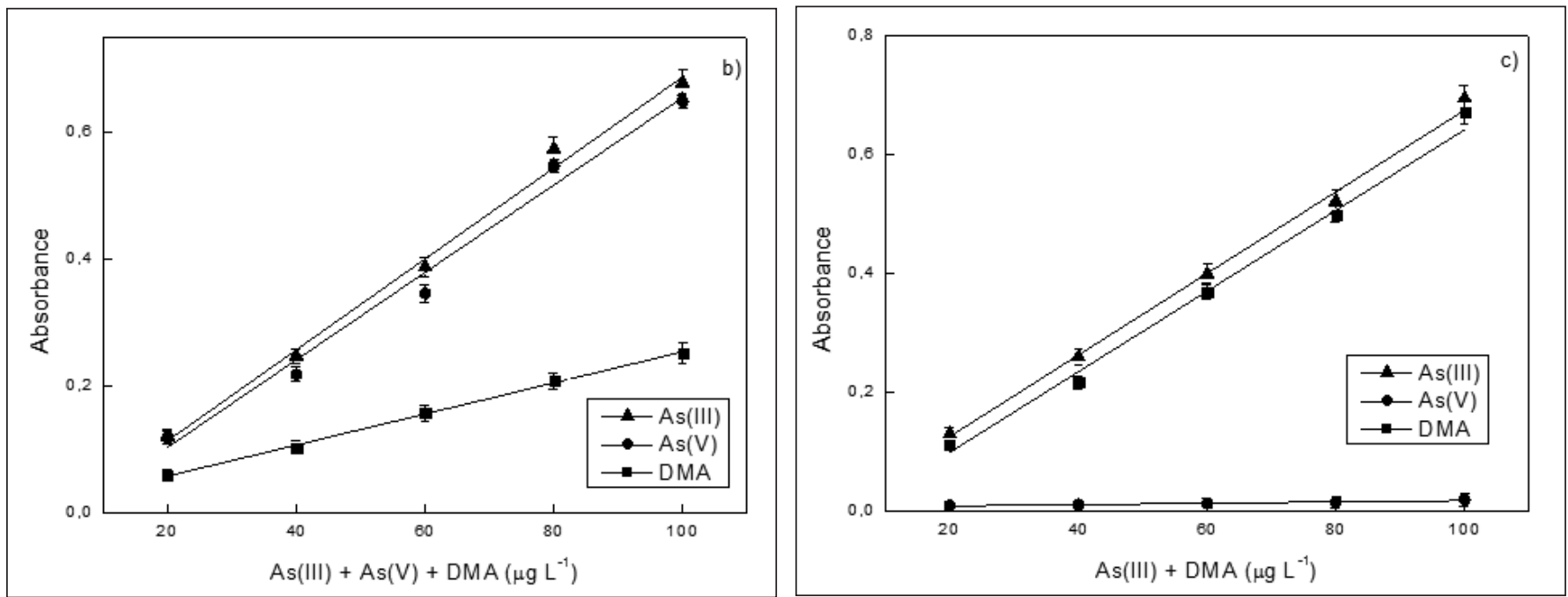

Fig. $3(a, b, c)$. Calibratian curves in different acid concentration: (a) $2 \%\left(v \cdot v^{-1)} \mathrm{HCl},(\mathrm{b}) 10 \%\left(v \cdot v^{-1}\right) \mathrm{HCl}_{\text {, (c) }} 2 \%\left(v \cdot v^{-1}\right) \mathrm{HNO}_{3}\right.$

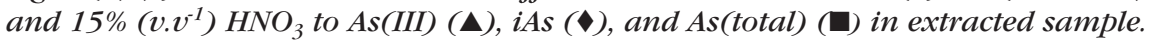


in Figure 4, good results of close to $90 \%$ were obtained for the extracting solution of $\mathrm{HCl}$ and was adopted for this work. The results of the proposed ultrasonic liquid extraction (USLE) method has low detection limits and low sample consumption in comparison to other reported methods and could be used for quantitative speciation procedures.

\section{Sample Analysis}

After evaluating the essential parameters for best results of HGFAAS, the procedure was applied to the determination of As(III), As(V) [iAs], and DMA [As(total)] in water, sediments, and plants. The calibration curves in 20-100 $\mathrm{g} \mathrm{L}^{-1}$ for As(III), 50-150 $\mathrm{g} \mathrm{L}^{-1}$ for As(V), and 30-100 $\mu \mathrm{g} \mathrm{L}^{-1}$ for DMA were built up. For both curves, typical

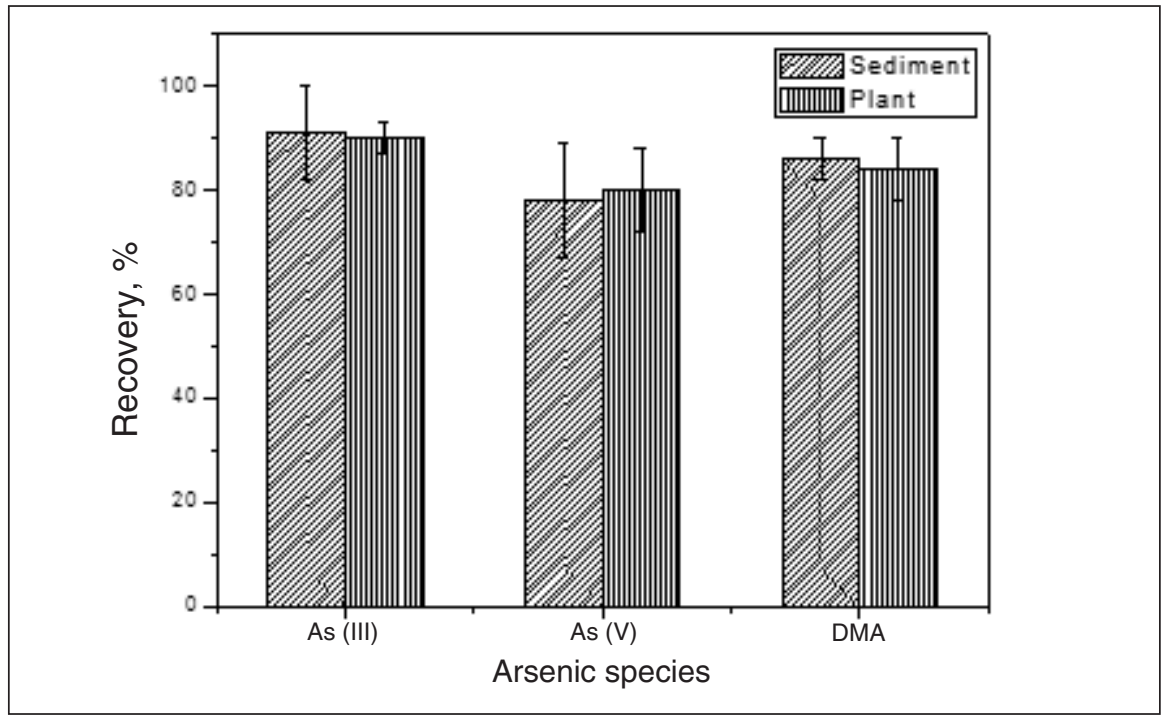

Fig. 4. Sample preparation efficiency using USLE to arsenic speciation in environmental samples using $6.0 \mathrm{~mol} \mathrm{~L}^{-1}$ bydrochloric acid.

TABLE II

Comparison of Characteristic Performance Data Obtained by Proposed Extraction Method and Other Reported Techniques for As Speciation

\begin{tabular}{lllll}
\hline Samples & $\begin{array}{l}\text { Detection } \\
\text { Technique }\end{array}$ & $\begin{array}{l}\text { Extraction/ } \\
\text { Digestion }\end{array}$ & $\begin{array}{l}\text { LOD } \\
\left(\mu \mathrm{g} \mathrm{L}^{-1}\right)\end{array}$ & References \\
\hline $\begin{array}{l}\text { Rice, Chicken } \\
\text { Muscle, Fish } \\
\text { and Soil }\end{array}$ & HPLC-ICP-MS & $\begin{array}{l}\text { Ultrasound } \\
\text { probe }\end{array}$ & $0.13--0.19$ & $(21)$ \\
Soil & HPLC-HG-AAS & $\begin{array}{l}\text { Ultrasound } \\
\text { probe }\end{array}$ & 7.0 & $(22)$ \\
Mushrooms & HG-AFS & $\begin{array}{l}\text { Ultrasound } \\
\text { water bath }\end{array}$ & 6.5 & $(23)$ \\
$\begin{array}{l}\text { Chards and } \\
\text { Aubergines }\end{array}$ & HG-AFS & $\begin{array}{l}\text { Ultrasound } \\
\text { water bath }\end{array}$ & 3.1 & \\
$\begin{array}{l}\text { Water, Sediment } \\
\text { and Plants }\end{array}$ & HG-FAAS & $\begin{array}{l}\text { Ultrasound } \\
\text { water bath }\end{array}$ & $3.1,5.7$, & $\begin{array}{l}\text { This } \\
\text { Work }\end{array}$ \\
\hline
\end{tabular}

correlation coefficients of better than $0.9967,0.9828$, and 0.9898 were obtained for As(III), As(V), and DMA, respectively. A total of nine real environmental samples were analyzed using the proposed sample preparation USLE method. The concentrations of each species in water, sediment, and plants were below the limit of detection. The precision of the measurements $(n=12)$, calculated as \%RSD, was in the $0.1-7.6 \%$ range. The limits of detection were $3.1 \mu \mathrm{g} \mathrm{L}^{-1}$ for As(III), $5.7 \mu \mathrm{g} \mathrm{L}^{-1}$ for As(V), and $3.8 \mu \mathrm{g} \mathrm{L}^{-1}$ for DMA. According to the National Council of the Environment (CONAMA, Brazil), the maximum tolerable As(total) level in environmental samples is $35 \mathrm{mg} \mathrm{kg}^{-1}$. Thus, the limits of detection for As speciation obtained with the proposed method are low and similar to other techniques reported in the literature (Table II). The accuracy of the proposed method was also evaluated by addition/recovery tests, and recoveries obtained were $83-100 \%$ for As(total) (Table III).

\section{CONCLUSION}

The proposed method is simple, fast, low cost, and highly sensitive for the quantitative determination of As(III), As(V), and DMA species in water, sediment, and plants. The extraction procedure is simple and very efficient for As speciation in environmental samples, requires only 10 minutes for sample preparation and no sample digestion steps. The methodology provides satisfactory analytical parameters with a limit of detection for As(III), As(V), and DMA of 3.1, 5.7, and $3.8 \mu \mathrm{g} \mathrm{g}^{-1}$, respectively, accuracy of $83-100 \%$, and precision (lower than $8.0 \%$ ) calculated as \%RSD.

\section{ACKNOWLEDGMENT}

The authors thank the Fundação de Apoio ao Desenvolvimento do Ensino, Ciência e Tecnologia do Estado de Mato Grosso do Sul, for the fellowships and to 
TABLE III

Concentrations (mean \pm standard deviation, $n=3$ ) and Recovery Percentages of As(III), As(V), and DMA in Water, Sediment, and Plant Samples After USLE Using the Proposed Acid Medium by HG-FAAS

\begin{tabular}{lccc}
\hline Samples & $\begin{array}{c}\text { Added }\left(\mu \mathrm{L} \mathrm{L}^{-1}\right) \\
\text { As(III) + As(V) } \\
\text { + DMA }\end{array}$ & $\begin{array}{c}\text { Found }\left(\mu \mathrm{g} \mathrm{L}^{-1}\right) \\
\text { As } \\
\text { Determined }\end{array}$ & $\begin{array}{c}\text { Recovery (\%) } \\
\text { As(III) + As(V) } \\
\text { + DMA }\end{array}$ \\
\hline Water 1 & $50+30+50$ & $119.8 \pm 3.4$ & 92.15 \\
Water 2 & $50+50+30$ & $120.7 \pm 2.1$ & 92.85 \\
Water 3 & $30+50+50$ & $129.9 \pm 5.6$ & 99.92 \\
Sediment 1 & $50+30+50$ & $109.8 \pm 5.1$ & 84.46 \\
Sediment 2 & $50+50+30$ & $118.3 \pm 3.8$ & 91 \\
Sediment 3 & $30+50+50$ & $120.4 \pm 4.5$ & 92.61 \\
Plant 1 & $50+30+50$ & $108.8 \pm 3.2$ & 83.69 \\
Plant 2 & $50+50+30$ & $121.1 \pm 4.6$ & 93.15 \\
Plant 3 & $30+50+50$ & $110.3 \pm 5.3$ & 84.85 \\
\hline
\end{tabular}

Coordenação de Aperfeiçoamento de Pessoal de Nivel Superior (CAPES) for the fellowship to B.S.P.

Received June 18, 2015.

\section{REFERENCES}

1. C M. Barra, R. E. Santelli, J. J. Abrão and M. Guardia, Química Nova 23(1), 58 (2000).

2. T. Guerin, A. Astruc and M. Astruc, Talanta 50, 1 (1999).

3. A.L. Moretto and S. Cadore, Microchim. Acta 146, 239 (2004).

4. B K. Mandal and K.T.Suzuki, Talanta 58,201 (2002).

5. L. Kozak, K. Skolasin'ska and P. Niedzielski, Chemosphere 89, 257 (2012).

6. K. Wrobel, K. Wrobel and J.A. Caruso, J. Anal. Bioanal. Chem. 381, 317 (2005).

7. K. Hirose, Anal. Sciences 22, 55 (2006).

8. R. F. Lobinski, Fresenius J. Anal. Chem. 369, 113 (2001).

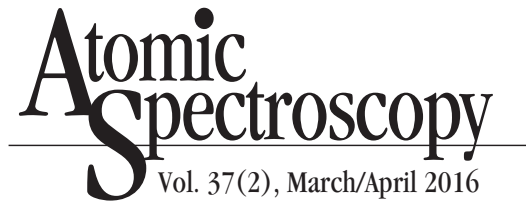

20. C.C. Nascentes, M.S. Korn, S. Clarivaldo, and M.A.Z. Arruda, J. Braz. Chem. Soc. 12(1), 57 (2001).

21. E. Sanz, R. Muñoz-Olivas and C. Cámara, J. Chrom. A. 1097, 1 (2005).

22. A. Marı?n, A. López-Gonzálvez, and C. Barbas, Anal. Chim. Acta. 442, 305 (2001).

23. M.E. Sigrist and H.R. Beldomenico, Spectrochim. Acta Part B, 59(7), 1041 (2004).

24. M.N.M. Reyes, M.L. Cervera, R.C. Campos and M. de la Guardia, Talanta 75(3), 811 (2008).

25. L.A. Currie, Anal. Chim. Acta 391 , 105 (1999). 